\title{
Spatial variation analysis of soil properties using spatial statistics: a case study in the region of Sabalan mountain, Iran
}

\author{
Ardavan Ghorbani, Samaneh Mohammadi Moghaddam, Kazem Hashemi Majd \& Naser Dadgar
}

Keywords: spatial variation, interpolation, IDW, Kriging, Cokriging, Natural Monument, Ardabil province

\section{Abstract}

Detailed soil information and soil maps are essential for the monitoring, management, conservation and restoration of natural ecosystems, rangelands and protected areas. Semi-automated mapping methods have advantages over conventional ones, and the selection of the best interpolation method and accurately predicted soil property maps are important for effective management and conservation strategies. Spatial soil information is important also for managing natural resources, predicting soil properties, improving sampling designs in future agro-ecological studies, and for assessing protected areas. We investigated the suitability of different interpolation methods for spatial variability predictions and for studying various soil properties within a rangeland ecosystem and the Sabalan National Natural Monument protected area, in northwestern Iran. Soil samples were collected randomly from a depth of 0-30 $\mathrm{cm}$, and various properties were measured in the laboratory. Normality of data was examined and spatial statistics was applied to determine spatial variation of the properties. Interpolation methods of inverse distance weighting, Kriging and Cokriging were applied and compared for suitability. Results were evaluated using crossvalidation. The results of applying spatial statistics demonstrated that soil properties had spatial dependence; Cokriging emerged as the most accurate technique overall.
Profile

Protected area

\section{Sabalan National}

Natural Monument

Mountain range

Alborz mountain range

Country

Iran

\section{Introduction}

Soil spatial variability evaluation can be made on scales ranging from the micro-level (millimetres) to the plot level (metres), up to landscape (kilometres) scale (Garten et al. 2007). Soil information and knowledge of spatial soil variation are important, having useful applications such as enhancing natural resources management (Wang et al. 2009), management of protected areas (Zinck 1995; Varallyay et al. 1998; Eagles \& McCool 2002; Majaliwa et al. 2010), predicting soil properties at unsampled locations (Wei et al. 2008; Liu et al. 2009), improving sampling designs for future agro-ecological studies (Yan et al. 2007), and evaluating protected areas (Majaliwa et al. 2010).

Spatial statistics is a powerful tool for spatial variability evaluations (Sauer et al. 2006); several studies have used spatial statistics to determine spatial variability of soil properties (Wei et al. 2008; Glendell et al. 2014; Longa et al. 2014; Li et al. 2015).

The most commonly used spatial statistical methods are inverse distance weighting (IDW), and Kriging and Cokriging interpolations (ESRI 2012; Gong et al. 2014). Kriging is a widely used stochastic method and is generally considered the best linear unbiased estimator, as it minimizes variance of the estimation error (Webster \& Oliver 2001; Dai et al. 2014). The method has shown considerable advantages in making predictions of soil properties when compared with deterministic interpolation methods (Liu et al. 2008, 2009; Worsham et al. 2010). Many studies have compared the accuracy of IDW and Kriging and have variously reported which is the more successful method. For example, Yasrebi et al. (2009) evaluated and compared Ordinary Kriging and IDW for the prediction of spatial variability of various chemical properties of soil, and concluded that the Kriging method performed better than IDW for all the properties examined. However, Robinson and Metternicht (2006) examined the performance of spatial interpolation techniques (IDW and Kriging) for mapping soil properties and concluded that Kriging performed better as an interpolated method for $\mathrm{pH}$ in the top soil, and lognormal Ordinary Kriging also performed better in measuring EC in the top soil. Sajid et al. (2013) evaluated and compared Kriging and IDW for the spatial analysis of soil bulk density. Their results indicated that neither method reflected the true variation of bulk density.

The Cokriging method is appealing because estimations consider other potentially important variables such as covariates (ESRI 2013). There are several other advantages of using Cokriging (Pardo-Iguzquiza et al. 2015): (i) problems of classical Indicator Cokriging, such as estimates outside the interval $(0,1)$ and order relations, are avoided; (ii) secondary variables (e. g. topographic parameters) can be contained in the estimation of probability maps; (iii) uncertainty maps (versus probability maps) can be obtained; (iv) there are modelling advantages, because variograms and cross-variograms of real variables do not have the restrictions of indicator variograms and indicator crossvariograms (Pardo-Iguzquiza et al. 2015). It appears 


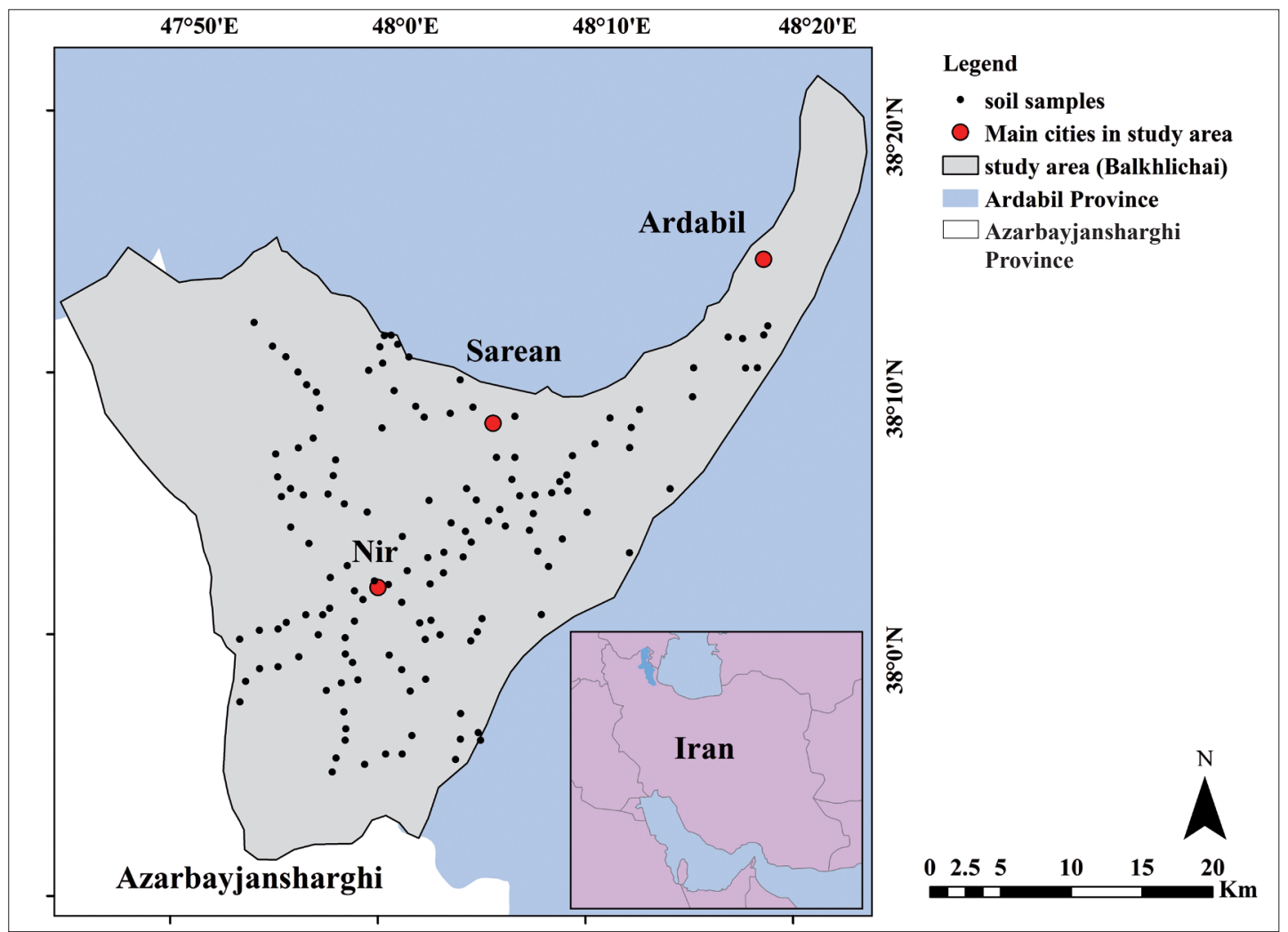

Figure 1 - Location of the study area (Balkhlichai watershed), main cities in the study area, and sampling points in Ardabil province, Iran.

that the optimal method depends on circumferences, and parameters such as the nature of the targets to be estimated (e.g. ground arsenic concentration and rainfall) (Wu et al. 2006). Because of the benefits of data transformation and Cokriging in making predictions, $\mathrm{Zn}$ was assessed using a georeferenced set of data from northern North Dakota. Cokriging on Zn, using $\mathrm{OC}$ or $\mathrm{pH}$ as auxiliary variables, was consistently more effective than Kriging on $\mathrm{Zn}$ alone. Considering the importance of mapping soil properties, the objectives of this study were to: (i) compare the accuracy of the interpolation techniques IDW, Kriging and Cokriging, and select the most suitable technique(s) for future studies in soil mapping; (ii) investigate changes in various soil properties on the southeastern slopes of Sabalan mountain. The aim was to create a framework that was appropriate for a particular soil, in order to preserve, restore and reform rangelands and protected areas. Maps produced in this study can be used in future studies to determine the relationship between these elements and parent material, as well as in analysing land use in other areas. They can also be used in future studies of these particular rangelands and of this protected area in order to enhance natural resource management, and to predict soil properties at unsampled locations. In addition, the maps can be of use in improving sampling designs, providing a baseline for future studies.

\section{Methods}

\section{Area under study}

The area under study is located at 1150 to $4811 \mathrm{~m}$ a.s.l., at $47^{\circ} 45^{\prime} \mathrm{E}$ to $48^{\circ} 23^{\prime} \mathrm{N}$ (at the Balkhlichai watershed, southeast of Sabalan mountain, Ardebil province, Iran; see Figure 1). It falls partly within the Sabalan National Natural Monument protected area. In terms of its ecological abiotic and biotic factors, the area can be divided into four main utilization and vegetative units: (i) plains with gentle slope (less than $12 \%$ ) and an elevation of 1150 to $1500 \mathrm{~m}$ (mainly agricultural, residential and industrial areas, and sparsely used rangeland in areas with limited slope; the rangeland is grazed mainly by rural livestock); (ii) hilly areas, intermediate between the plains and Sabalan mountain, at an altitude of 1500 to $2500 \mathrm{~m}$, with slope variation and relatively deep soil (the lower slopes are cultivated as dry farming; the rest of the area is rangeland). Rural livestock and the livestock of the Shahsevan nomads graze rangelands in these areas, which are extremely degraded; (iii) low mountainous areas of Sabalan mountain, at 2500 to $3600 \mathrm{~m}$, with limited rangeland use; mainly grazed by the Shahsevan nomads' livestock; these areas are also extremely overgrazed; (iv) elevated mountainous areas, over $3600 \mathrm{~m}$, also grazed by the Shahsevan nomads' livestock; area designated as the Sabalan National Natural Monument (6 $643 \mathrm{ha}$ ) by the Department of the Environment of Iran (Ghorbani et al. 2013, 2014, 2015). The area un- 
der study has temperate summers and cold winters; for three to four months of the year, it is covered with snow and ice; mid-June to mid-October is the dry season. At lower altitudes, the climate is semi-arid; high altitudes are cold and semi-arid (Ghorbani et al. 2013). Despite considerable anthropogenic effects, plant species diversity is high; some plants, such as Artemisia melanolepis Boiss, and Nepeta menthoides Boiss and Buhse, are endemic to Iran; Nepeta menthoides Boiss and Buhse has been reported only in Iran's Sabalan mountain. Due to the high anthropogenic effects on the habitat of Sabalan more broadly, wildlife variation is low, particularly in unprotected areas. On the other hand, in the protected area (the Sabalan National Natural Monument), there is still a considerable variety of flora (more than 600 species) and fauna (more than 40 species). The wildlife includes birds such as Tetraogallus caspiuscaspius, and mammals such as Ovis orientalis gmelini and Capra aegagrusaegagrus; Tetraogallus caspiuscaspius and Ovis orientalis gmelini are of particular importance because they are found only on Sabalan mountain (Sheikh \& Sheikh 2006).

\section{Soil sampling}

The study area is mountainous and has limited access only, by nomadic roads. Thus, it was impossible to collect samples in a systematic grid format and some parts remained unsampled. Soil samples were therefore collected randomly, according to accessibility by road, from 151 sites (Figure 1). The criteria used in selecting sites for soil sample collection were that the sites had to be: (i) at least $1000 \mathrm{~m}$ away from each other; (ii) in the natural rangelands; (iii) some distance from villages, cultivated land and recreational areas to avoid edge effects; (iv) representative of all landforms and soil types of the area in terms of elevation, slope and aspect. As the region is mountainous, samples were taken from a depth of 0 to $30 \mathrm{~cm}$ (the effective depth of plant roots; Ghorbani et al. 2013, 2015). In each site, a $100 \mathrm{~m}$ transect was established perpendicular to the main slope (for vegetation sampling for another study). Soil samples were collected from the start, middle and end of each transect and mixed together as one sample for each site. The position of each soil sample was recorded using GPS. Soil samples were transferred to the laboratory of the University of Mohaghegh Ardabili and prepared for analysis.

\section{Measuring soil properties}

Prior to analysis, all soil samples were air dried and hand-sieved through a $2 \mathrm{~mm}$ mesh to remove roots and other debris. $\mathrm{pH}, \mathrm{EC}, \mathrm{OC}, \mathrm{CaCO}_{3}$, absorbable $\mathrm{K}$ and $\mathrm{P}$, and percentages of sand, silt and clay were measured according to standard procedures. $\mathrm{pH}$ and $\mathrm{EC}$ were measured using a $\mathrm{pH}$ meter and WTW (Bauer \& Knorr 2004) respectively. OC was measured using the Blac-Valkly (Sato et al. 2014) method; $\mathrm{CaCO}_{3}$ was measured by neutralization with acid and titration (Bitter et al. 2010); K and P were measured by ammonium acetate (Patel et al. 2014) and Olsen methods (Betencourt et al. 2012) respectively. The Baykas hydrometer (Kettler et al. 2001) method was used to determine soil texture in terms of sand, silt and clay, which were measured without separation.

\section{Conventional statistical analyses}

Descriptive statistics, including the mean, standard deviation, coefficient of variation, maximum, minimum, Kurtosis, Skewness and Kolmogov-Smirnov $(\mathrm{K}-\mathrm{S})$ tests, were performed for each of the soil variables measured. Descriptive statistical analyses were performed using the SPSS16.0 software package (SPSS Inc., USA).

\section{Spatial statistics of estimated soil properties}

Spatial statistical methods were used to study spatial variability of soil properties. The semivariograms were calculated from the data, and fitted models were derived for the properties of each soil sample. In the second stage, predictions were made for the unsampled locations. The semivariogram of each soil property was constructed using equation (model) 1 :

$$
\gamma(h)=1 / 2 N(h) \sum_{i} \sum_{i+h}\left[z(i)-z(i+h]^{2}\right.
$$

where $\gamma$ is the semi-variance for $\mathrm{N}$ data pairs separated by a distance lag $h$, and $z$ is the variable under consideration at positions $i$ and $i+h$. As semivariogram construction assumes a Gaussian distribution (Reimann \& Filzmoser 2000; Olea 2006; Wang et al. 2015), variables were transformed if necessary to approximate normality and stabilize variance (Goovaerts 1999; Wang et al. 2015). Data was detrended by fitting low-order polynomials according to the exhibited trend (if existent) to account for any systematic variation (i.e. global trend) and hence satisfy the assumption of stationarity (Bekele \& Hudnall 2006; Sauer et al. 2006; Wang et al. 2015). Thus, after detrending, particular residuals were used to determine standardized isotropic semivariograms in the soil sample from each location. Therefore, according to the distribution of the collected samples, anisotropy (the effect of direction on the intensity of spatial dependence) was not considered in the interpretation, as such an analysis would have required a higher number of samples in each direction in order to build a stable semivariogram. Isotropic characterization of spatial dependence is reportedly more suitable when there are only a small number of samples (Davidson \& Csillag 2003). After the semivariograms had been constructed, theoretical semivariogram models were fitted to the data, by selecting the model with the lowest residual sum of squares and highest $\mathrm{R}^{2}$ (e.g. Wei et al. 2008; Liu et al. 2009; Wang et al. 2009). In these models, $C_{o}$ is the nugget, $C_{o}+C$ is the sill, and $a$ is the range. These parameters were used to describe and compare the spatial structure of soil properties. Soil variables were then interpolated using IDW, Kriging and Cokriging methods. 
$\mathrm{PH}$ Variogram

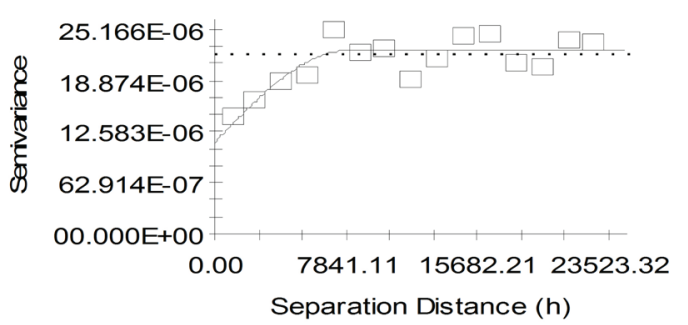

OC Cross-Variogram

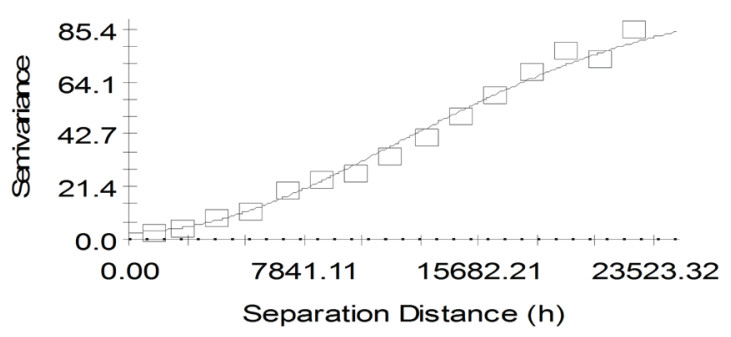

K Variogram
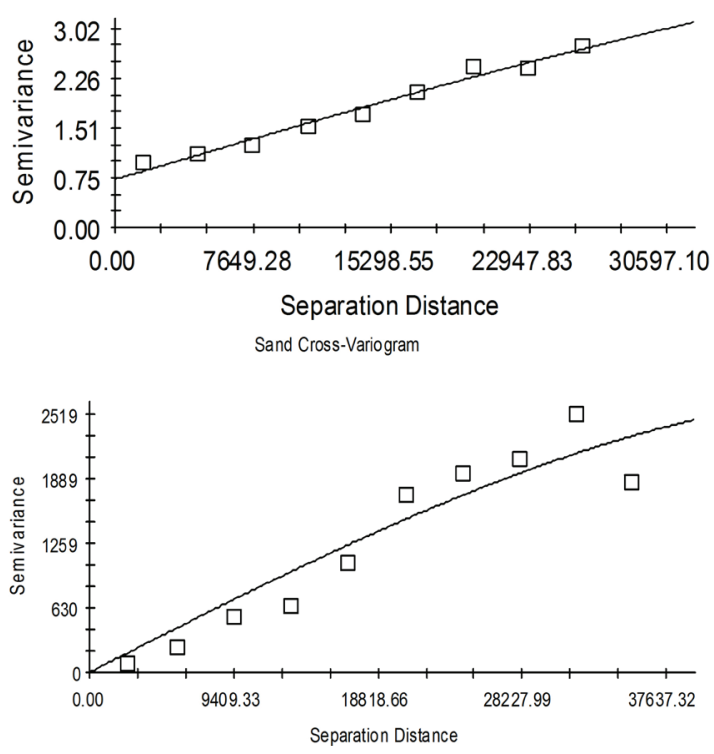

Clay Cross Variogram

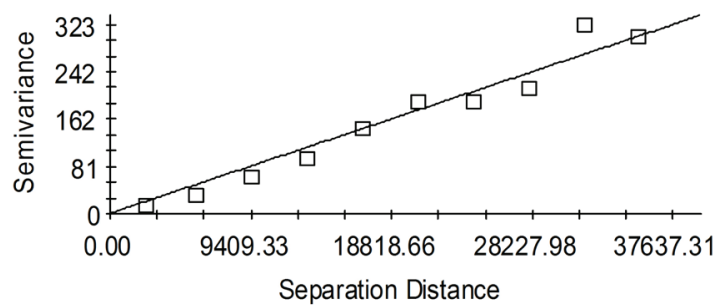

Based on minimization of the sum of the squared deviations between experimental and theoretical semivariograms, a spherical model (equation 2), an exponential model (equation 3), and a Gaussian model (equation 4) were selected for the further investigation of spatial structure:
EC Cross-Variogram

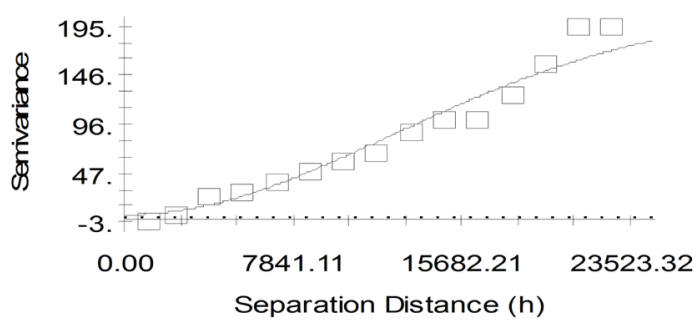

CaCo3 Cross-Variogram

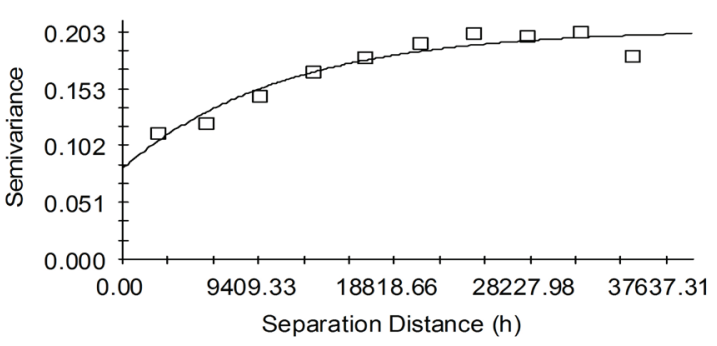

P Cross-Variogram

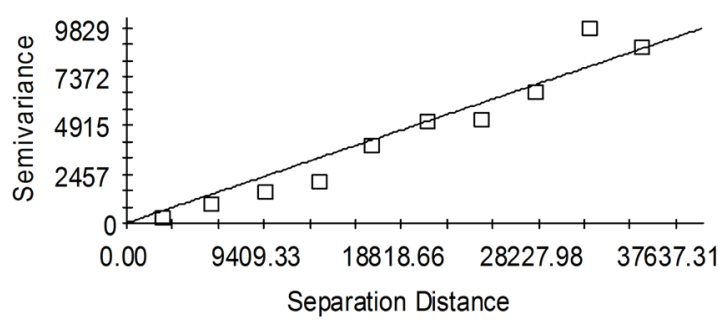

Silt Cross-Variogram

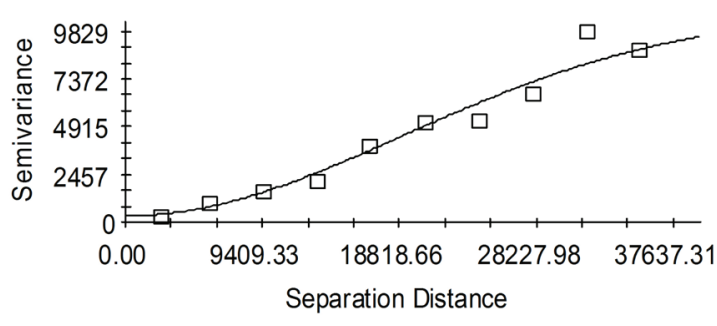

Figure 2 - Variograms and cross-variogams of $p H, E C$, $\mathrm{CaCO}_{3}, \mathrm{OC}, \mathrm{K}, \mathrm{P}$, sand, silt and clay

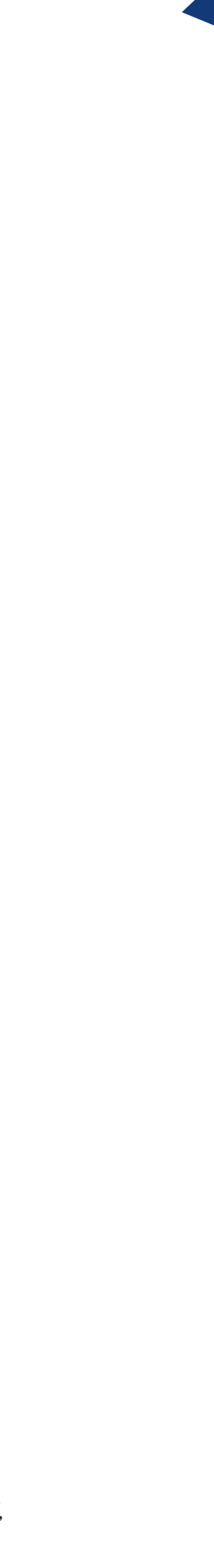


Table 1 - Descriptive statistics for soil properties.

\begin{tabular}{|l|r|r|r|r|r|r|l|}
\hline $\begin{array}{l}\text { Soil } \\
\text { properties }\end{array}$ & Mean & Median & SD & Variance & Skewness & Kurtosis & CV \\
\hline $\mathrm{pH}$ & 7.76 & 7.75 & 0.27 & 0.07 & 1.04 & 7.97 & 0.27 \\
\hline $\mathrm{EC} \mathrm{(ds/m)}$ & 0.25 & 0.20 & 0.26 & 0.06 & 5.46 & 34.70 & 0.29 \\
\hline $\mathrm{OC}(\%)$ & 1.32 & 1.15 & 0.80 & 0.64 & 0.94 & 3.43 & 0.60 \\
\hline $\mathrm{CaCO}_{3}(\%)$ & 9.68 & 8.20 & 7.99 & 63.84 & 1.30 & 4.67 & 0.82 \\
\hline $\mathrm{K}(\mathrm{mg} / \mathrm{kg})$ & 351.40 & 274.68 & 254.00 & 63862.00 & 2.60 & 13.11 & 0.71 \\
\hline $\mathrm{P}(\mathrm{mg} / \mathrm{kg})$ & 0.31 & 2.37 & 833.00 & 53.14 & 50.00 & 28.85 & 0.54 \\
\hline Sand (\%) & 0.20 & 2.60 & 160.00 & 44.17 & 42.65 & 12.63 & 0.28 \\
\hline Silt (\%) & 45.32 & 45.32 & 14.94 & 223.20 & 0.17 & 1.94 & 0.32 \\
\hline Clay (\%) & 10.33 & 6.01 & 8.74 & 76.38 & 2.78 & 13.00 & 0.84 \\
\hline
\end{tabular}

Table 2 - The parameters of the semivariogram models.

\begin{tabular}{|c|c|c|c|c|c|c|c|}
\hline $\begin{array}{l}\text { Soil } \\
\text { properties }\end{array}$ & Model & $\mathrm{C}_{0}$ & $C+C_{0}$ & \begin{tabular}{|l} 
Range \\
{$[\mathrm{m}]$}
\end{tabular} & $\mathrm{C} /\left(\mathrm{C}+\mathrm{C}_{0}\right)$ & $\mathbf{R}^{2}$ & RSS \\
\hline $\mathrm{pH}$ & Exponential & 0.06 & 0.11 & 33980 & 0.50 & 0.76 & 0.04 \\
\hline $\mathrm{EC}(\mathrm{ds} / \mathrm{m})$ & Gaussian & 4.70 & 210.00 & 30570 & 0.97 & 0.95 & 0.00 \\
\hline OC (\%) & Gaussian & 2.90 & 96.80 & 29860 & 0.97 & 0.98 & 0.33 \\
\hline $\mathrm{CaCO}_{3}(\%)$ & Exponential & 0.08 & 0.20 & 11190 & 0.60 & 0.92 & 0.00 \\
\hline $\mathrm{K}(\mathrm{mg} / \mathrm{kg})$ & Spherical & 0.73 & 4.27 & 66150 & 0.82 & 0.97 & 0.06 \\
\hline $\mathrm{P}(\mathrm{mg} / \mathrm{kg})$ & linear & 10.00 & 10130.00 & 40740 & 0.99 & 0.95 & 0.00 \\
\hline Sand (\%) & Spherical & 1.00 & 2721.00 & 53470 & 1.00 & 0.91 & 0.80 \\
\hline Silt (\%) & Gaussian & 320.00 & 10750.00 & 26860 & 0.97 & 0.95 & 0.00 \\
\hline Clay (\%) & linear & 1.00 & 399.00 & 46520 & 0.99 & 0.96 & 0.00 \\
\hline
\end{tabular}

where $b$ is lag distance, $C_{0}$ the nugget effect (the local variation occurring at scales finer than the sampling interval, or fine-scale variability, measurement or sampling error), $C_{0}+C_{1}$ is the total variance, and $a$ is the range of spatial dependence.

Continuous maps of individual attributes were generated by point Kriging without drift, which estimates values of points at the grid nodes (Candela et al. 1988). Construction of semivariograms and model fitting were performed in $\mathrm{GS}^{+}$version 5 (Gamma Design Software, USA); ArcGIS10.2 (ESRI, ArcGIS Desktop, USA) geostatistical analyst tool was used for interpolation and mapping.

Assessment of the accuracy of predictions

Cross-validation was used to test the accuracy of the maps produced, and MAE (equation 5), MBE (equation 6) and RMSE (equation 7) were used to measure the accuracy (Wang et al. 2015). The mean absolute error (MAE) is a useful measure widely used in model evaluations (Elshorbagy et al. 2010). Elshorbagy et al. reported that the root mean square error (RMSE) is used as a standard statistical metric to measure model performance in meteorology, air quality, climatic and soil studies. Furthermore, they reported that while MAE gives the same weight to all errors, RMSE penalizes variance as it gives errors with larger absolute values more weight than errors with smaller absolute values. In addition, MBE is a measure of overall bias error or systematic error and is usually written as a percentage error.
$M A E=\frac{1}{N} \sum_{i=1}^{N}\left|O_{i}-P_{i}\right|$

$M B E=\frac{1}{N} \sum_{i=1}^{N}\left(O_{i}-P_{i}\right)$

$R M S E=\sqrt{\frac{\sum_{i=1}^{N}\left(O_{i}-P_{i}\right)^{2}}{N}}$

where $N$ represents the number of instances presented to the model; Oi and Pi represent observed and predicted equals; and $\mathrm{O}$ and $\mathrm{P}$ represent the means of the corresponding variables.

\section{Results and discussion}

\section{Analysis of descriptive statistics}

Descriptive statistics, including mean, median, standard deviation (SD), variance, skewness, kurtosis and coefficient of variation (CV) for soil properties, are presented in Table 1. Most of the soil properties did not have a normal distribution; exceptions were $P$ and percentage of sand. Since the deviation from the normal distribution may have an undesirable effect on statistical analysis, especially in semivariogram computation, this study applied several normalization functions, and the inverse method was then used for normalization of silt, $\mathrm{CaCO}_{3}$ and $\mathrm{K}$ using a logarithmic converter, amount of soil OC using square root, clay content, EC and $\mathrm{pH}$.

\section{Results of spatial statistical analysis}

The results of semivariogram analysis for soil parameters showed that with normal distribution of samples, error rate reduced and solidarity and precision increased. As presented in Table 2 and Figure 2, a semivariogram of all parameters was derived as isotropic or independent of direction. Different soil variables followed different variogam models. For example, $\mathrm{CaCO}_{3}$ and $\mathrm{pH}$ conformed to an exponential model, while EC, OC and silt conformed to a Gaussian model. The same results are reported in Cobo et al. (2010), in which soil properties clay, silt, sand and $\mathrm{pH}$ were very well represented by spherical modelling, with variable parameters depending on the property and the area under evaluation. Moreover, Bitencourt et al. (2016) reported that physical properties of soil, including sand, clay and silt, followed the Gaussian model. Results of the spatial properties examined in this case also imply that most soil variables have strong spatial correlation, with the exception of $\mathrm{pH}$ and $\mathrm{CaCO}_{3}$, which have moderate spatial structure. Based on the results of semivariogram elements, it was observed that K, with $66150 \mathrm{~m}$, had the maximum impact domain, and $\mathrm{CaCO}_{3}$, with $11190 \mathrm{~m}$, had the smallest impact domain among the elements studied (Table 2). The corresponding results in Cobo et al. (2010), for the smallest and largest impact ranges, were for sand $(506 \mathrm{~m})$ and clay $(695 \mathrm{~m})$ respectively, which were very low in comparison to our results. If we look at the range of $\mathrm{K}(66150 \mathrm{~m})$, it can be concluded that the spatial structure of this para- 
meter, in comparison with that of other elements (e. g. lag distance), was much larger. This makes it possible to select greater values for the various elements, reducing the number of actual samples required, to estimate unsampled locations. Moreover, in the design of the sampling network for this parameter, it was possible to increase the sampling intervals.

\section{Selection of the best model}

After processing the appropriate model and extracting semivariograms from the data, the best interpolation method based on RMSE was selected. For pH and EC, a Simple Kriging interpolation method was selected; for OC, Disjunctive Cokriging; for $\mathrm{CaCO}_{3}, \mathrm{~K}$, silt and clay, Ordinary Cokriging; and for $\mathrm{P}$ and sand Indicator, Cokriging (see Tables 3 and 4). According to metrics such as MAE and RMSE, the Cokriging method had a lower error rate than Kriging. This could reflect the fact that the spatial distribution of soil properties was highly correlated with elevation, which tends to reduce variance estimation. Yanl et al. (2007) compared the Cokriging and Kriging methods for improved prediction and reduction of sampling density for soil salinity. They reported that, in all cases, the RMSE of the Cokriging estimation was significantly lower than for the Kriging estimation. Bameri et al. (2015) also report lower RMSE for Ordinary Cokriging in estimating OC using clay content as the covariant. This gave better results over the whole slope in comparison with the Kriging and IDW methods. In our study, using covariates such as elevation, which was highly correlated with the main variable (Ghorbani et al. 2015), resulted in an increase in accuracy in interpolation. Thus, for the prediction of soil properties (except $\mathrm{pH}$ ), in order to convert the point data to an area, we recommend the use of auxiliary variables that are highly correlated with the main variables, such as elevation.

\section{Spatial distribution of soil properties}

Figure 3 shows interpolated maps for soil variables based on the best derived models and methods. According to map 3a, which was produced using Simple Kriging, the average $\mathrm{pH}$ in the study area was 7.76 (Table 1). North and south of the area had higher estimates for $\mathrm{pH}(7.97-8.80)$. EC, in the entire area of study, was less than $0.61 \mathrm{ds} / \mathrm{m}$ (Figure $3 \mathrm{~b}$ ). Based on these results, there was a relationship between soil OC and elevation.

Figure $3 \mathrm{c}$ shows the map produced using discrete Cokriging for OC. The north and northwestern areas showed unexpectedly high OC content because in other areas rangeland vegetation cover in comparison was high (Ghorbani et al. 2013, 2014, 2015). In contrast, the samples taken at lower altitudes and in areas degraded by grazing showed lower soil OC. It seems that at higher elevations, reduced temperature and increased humidity led to a reduction in the decomposition of litter, causing an accumulation of OC (Franzluebbers 2002).
Table 3 - Results of interpolation methods for soil properties, showing the best model for each parameter.

\begin{tabular}{|l|l|l|l|r|}
\hline $\begin{array}{l}\text { Soil } \\
\text { properties }\end{array}$ & Method type & $\begin{array}{l}\text { Lag } \\
\text { size }\end{array}$ & Model type & RMSE \\
\hline $\mathrm{pH}$ & Simple Kriging & 2000 & Exponential & 0.00 \\
\hline $\mathrm{EC}(\mathrm{ds} / \mathrm{m})$ & Simple Cokriging & 1500 & Gaussian & 1.36 \\
\hline $\mathrm{OC}(\%)$ & Disjunctive Cokriging & 1000 & Gaussian & 0.27 \\
\hline $\mathrm{CaCO}(\%)$ & Ordinary Cokriging & 1500 & Gaussian & 0.36 \\
\hline $\mathrm{K}(\mathrm{mg} / \mathrm{kg})$ & Ordinary Kriging & 1500 & Gaussian & 0.23 \\
\hline $\mathrm{P}(\mathrm{mg} / \mathrm{kg})$ & Indicator Cokriging & 1000 & Exponential & 0.49 \\
\hline Sand $(\%)$ & Indicator Cokriging & 1800 & Exponential & 0.45 \\
\hline Silt $(\%)$ & Ordinary Cokriging & 2000 & Gaussian & 0.13 \\
\hline Clay $(\%)$ & Ordinary Cokriging & 1500 & Gaussian & 0.06 \\
\hline
\end{tabular}

Table 4 - Results of accuracy assessment of the various interpolation methods.

\begin{tabular}{|l|l|r|r|r|}
\hline $\begin{array}{l}\text { Soil } \\
\text { properties }\end{array}$ & Method type & MBE & MAE & RMSE \\
\hline $\mathrm{pH}$ & Simple Kriging & 0.00 & 0.00 & 0.00 \\
\hline $\mathrm{EC}(\mathrm{ds} / \mathrm{m})$ & Simple Cokriging & 0.06 & 0.07 & 0.25 \\
\hline $\mathrm{OC}(\%)$ & Disjunctive Cokriging & -0.04 & 0.22 & 0.27 \\
\hline $\mathrm{CaCO}_{3}(\%)$ & Ordinary Cokriging & 0.18 & 0.27 & 0.36 \\
\hline $\mathrm{K}(\mathrm{mg} / \mathrm{kg})$ & Ordinary Kriging & -0.03 & 0.11 & 0.23 \\
\hline $\mathrm{P}(\mathrm{mg} / \mathrm{kg})$ & Indicator Cokriging & 5.90 & 21.74 & 0.49 \\
\hline Sand $(\%)$ & Indicator Cokriging & 6.12 & 10.75 & 11.34 \\
\hline Silt $(\%)$ & Ordinary Cokriging & 0.04 & 0.11 & 0.13 \\
\hline Clay $(\%)$ & Ordinary Cokriging & 0.00 & 0.04 & 0.06 \\
\hline
\end{tabular}

The interpolated map (Figure 3d) of Ordinary Cokriging showed that the $\mathrm{CaCO}_{3}$ in the area did not have a random pattern, and was affected by elevation. Thus, the lowest amount of $\mathrm{CaCO}_{3}(0.8-15.6 \%)$ was mapped in the south and southeast at lower elevations. It seems that destructive activities such as overgrazing carried out in steep mountainous areas caused increased erosion and leaching into the soil, increased dissolution of limestone, and ultimately increased $\mathrm{CaCO}_{3}$ percentage in soil at lower altitudes.

Figure $3 \mathrm{e}$ shows the map for $\mathrm{K}$ content produced using the Ordinary Kriging method. The central and northeastern areas had higher amounts of K. Evaluation in the rangeland areas located below $2500 \mathrm{~m}$ a.s.l. may have been affected by changes such as dry farming, planting of high-yield varieties, and use of groundwater rather than surface water; these considerations may need further investigation. There was a radical change in $\mathrm{P}$ availability in the area.

As seen in Figure 3f, the northern part of the area had higher levels of P. Since rangeland vegetation in the mid-highland areas had dense cover, and absorbed $P$ from different layers of the soil, phosphorus accumulated at the soil surface after the destruction of the soil layers. Moreover, there were increasing amounts of $\mathrm{P}$ in the northeastern part of the study area.

Figure $3 g$ shows a map of sand evaluations and their variation. In the northern parts of the study area, as expected, high altitude rangeland had low soil depth, high slope and rocky outcrops in comparison with the lowland areas, which had deeper soil, and 

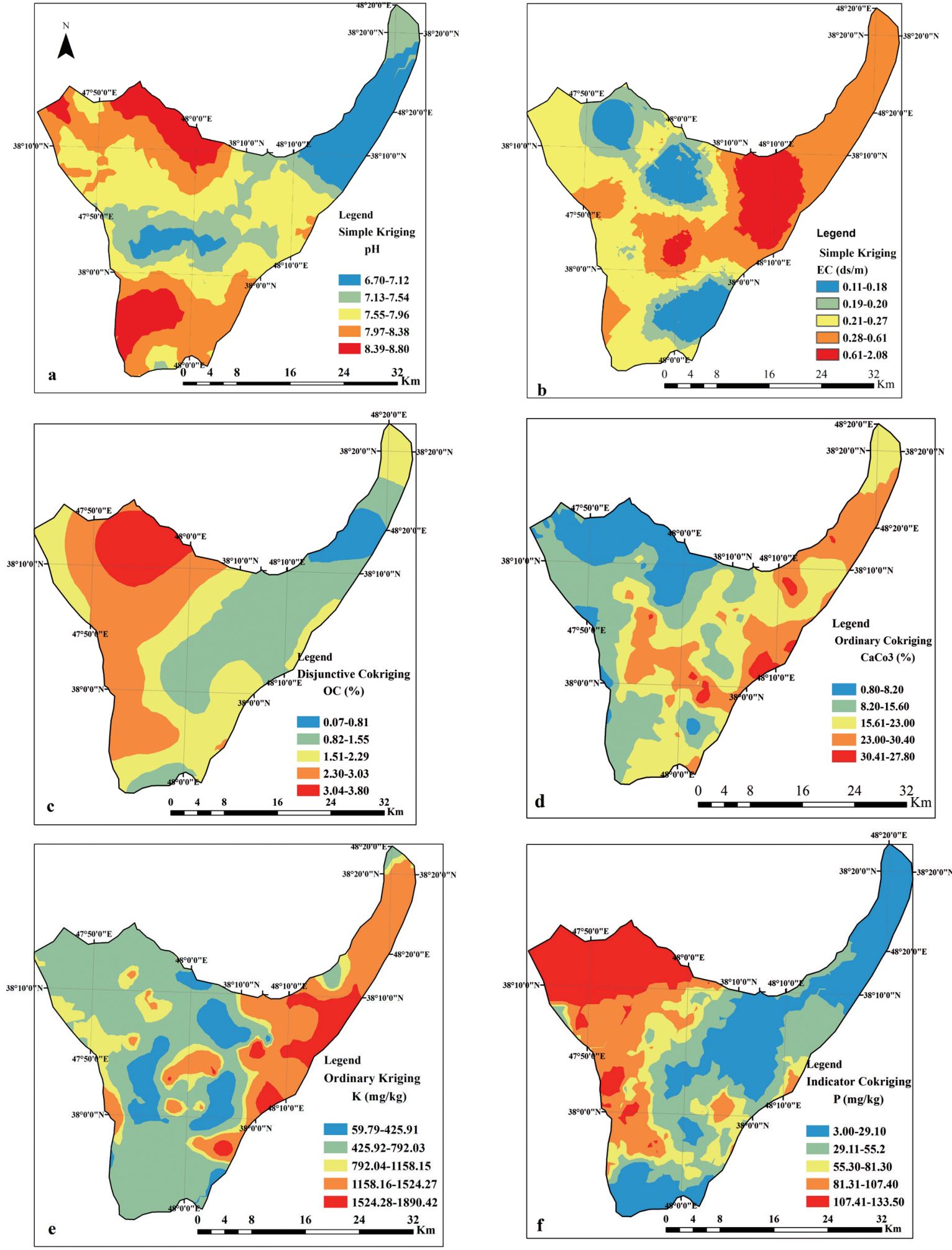

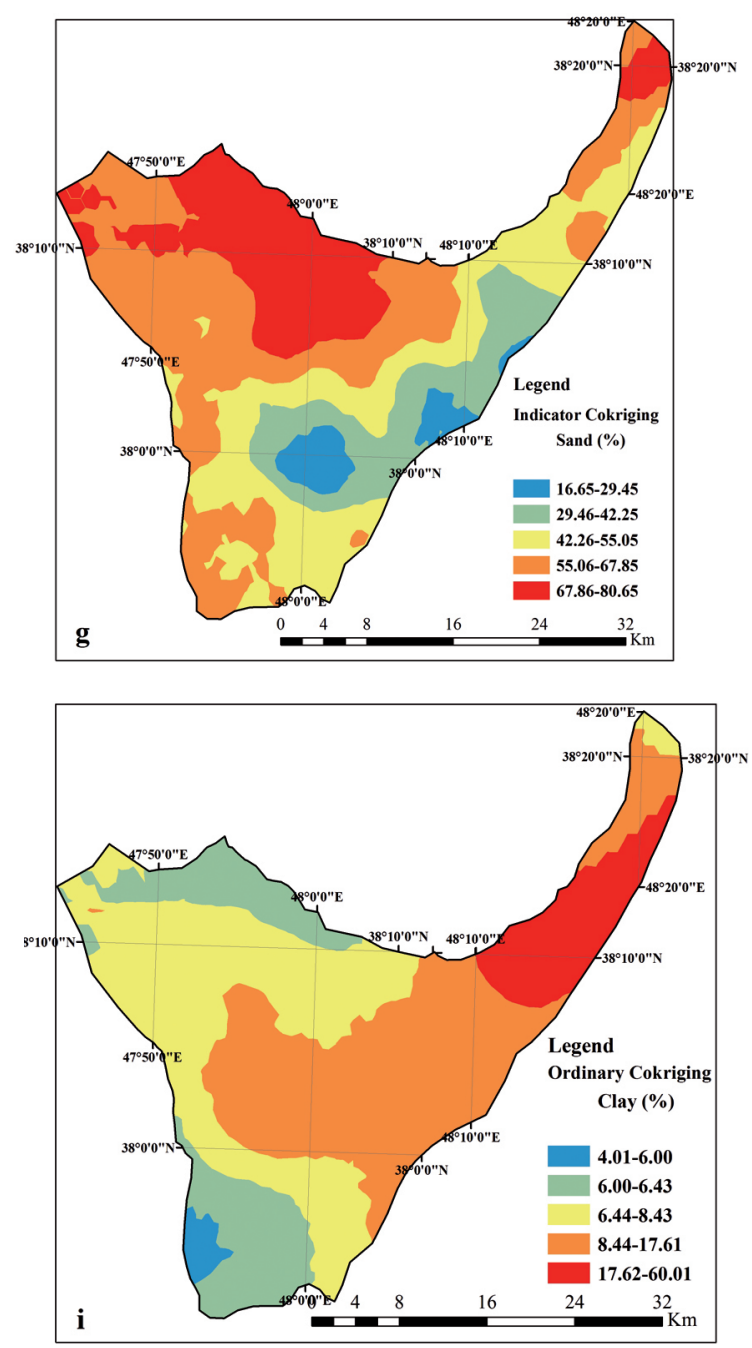

shallow slope in the south and east, which showed lower amounts of sand in the soil contents.

The spatial distribution of silt was almost the opposite of the OC distribution (Figure 3h). Mapping showed that where silt occurred, it did so in higher concentrations in the southeast, although overall this area had relatively little silt. In contrast, the percentage of silt was higher towards the north and west, in the steeper areas, as was expected because of the shallow soil and the low outcrops.

Figure $3 \mathrm{i}$ shows the map for clay content, which was as expected. However, the percentage of clay particles was lower towards the western areas.

\section{Application of results: emphasis on protected} area

Ecosystems, including rangelands and protected areas, require constant monitoring (Zinck 1995; Várallyayet et al. 1998; Hockings 2009), and soil maps are one of the basic sources of information in this regard (Webster \& Oliver 2000). Monitoring natural ecosystems and protected areas is necessary for the collection of reliable physical data, such as certain soil types and special soil features relating to broad geographical areas (e.g. natural rangelands), or smaller land units

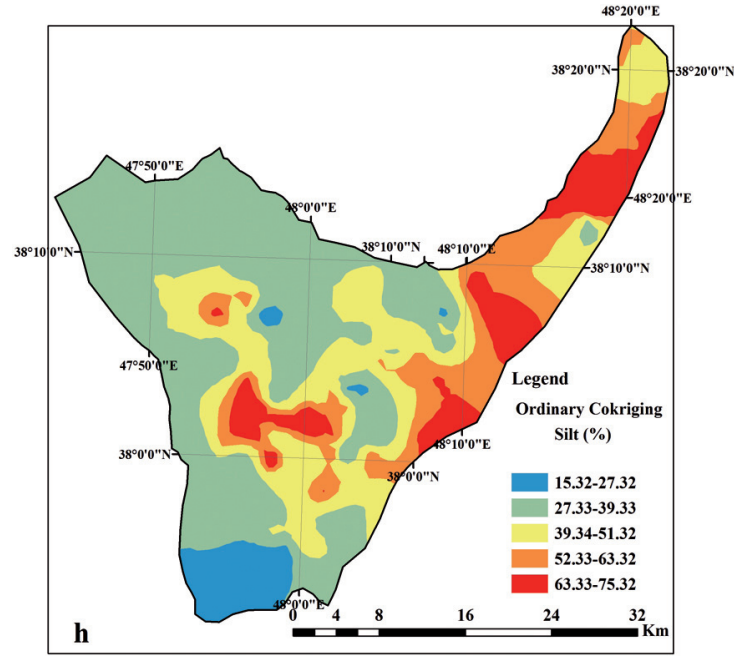

Figure 3 - Spatial distributions of soil properties; a) $p H$, b) $\mathrm{EC}$, c) $\mathrm{OC}$, d) $\mathrm{CaCO}_{3}$, e) $\mathrm{K}$, f) $\mathrm{P}, \mathrm{g}$ ) sand, b) silt, i) clay.

(such as protected areas). The availability of such information helps in the conservation, management and monitoring of biological and physical features of regions or land units (Alberta Natural Heritage Information Centre 2002).

Providing reliable physical data can enhance decision-making related to resource- and / or land-use. Data must be collected to help evaluate an area's biodiversity, such as presence, distribution, status and trends of plant species, and which species are at risk and to what extent. The impact of human activities also needs to be determined (Alberta Natural Heritage Information Centre 2002). Producing detailed information such as soil maps based on conventional methods is time-consuming but cost effective, particularly when these maps need to be produced every 5 to 10 years for monitoring purposes. Semi-automated methods are therefore needed to produce detailed soil information maps, including for the whole of Iran, and in particular for natural environments and protected areas such as Sabalan mountain and Sabalan National Natural Monument (Ghorbani et al. 2013, 2014, 2015). The results of this study provide basic information of interest for various fields of study, such as quantitative vegetation studies and ecotourism development plan- 
ning. Moreover, this study presents a method that can be applied to soil parameter mapping in other rangelands and protected areas.

\section{Conclusion}

We conducted this study in order to help overcome the need for relatively low-cost, detailed information. This study compared interpolation methods to determine the spatial distribution of soil properties, including $\mathrm{pH}, \mathrm{EC}, \mathrm{OC}, \mathrm{CaCO}_{3}, \mathrm{~K}, \mathrm{P}$, sand, silt and clay, on the southeastern slope of Sabalan mountain rangelands and at the Sabalan National Natural Landmark. Selection of the best interpolation method and accurately predicting soil property maps can help range management to conserve and restore the rangeland, and can be instrumental in identifying new areas to be protected and monitoring them.

The maps produced can be used to locate the distribution of soil properties and improve sampling design. Based on the results of the interpolation methods for soil variables, the Kriging method was found to be the best predictor for $\mathrm{pH}$ and $\mathrm{K}$; the Cokriging method was more suitable for other variables. Comparison among the Cokriging, Kriging and IDW methods showed that Cokriging produced more reliable results. In other words, although the application of the Kriging method in this study presented acceptable predictions, Cokriging increased the accuracy of the maps. This could reflect the fact that the spatial distribution evaluations for individual soil properties were highly correlated with elevation, which tends to reduce the variance of the predictions. Mapping the variables showed that $\mathrm{pH}, \mathrm{EC}$ and $\mathrm{OC}$ was effective in enhancing management efficiency.

\section{References}

Alberta Natural Heritage Information Centre 2002. Guidelines for natural heritage inventories in parks and protected areas. Parks and Protected Areas Division. Alberta Community Development, Edmonton, Alberta.

Bameri, A., F. Khormali, F. Kiani \& AA. Dehghani 2015. Spatial variability of soil organic carbon in different hill slope positions in Toshan area, Golestan Province, Iran: geostatistical approaches. Journal of Mountain Science 12(6): 1422-1433.

Bauer, B.A. \& D. Knorr 2004. Electrical conductivity: a new tool for the determination of high hydrostatic pressure-induced starch gelatinization. Innovative Food Science \& Emerging Technologies 5(4): 437-442.

Betencourt, E., M. Duputel, B. Colomb, D. Desclaux \& P. Hinsinger 2012. Intercropping promotes the ability of durum wheat and chickpea to increase rhizosphere phosphorus availability in a low $\mathrm{P}$ soil. Soil Biology \& Biochemistry 46: 181-190.

Bekele, A. \& W.H. Hudnall 2006. Spatial variability of soil chemical properties of a prairie - forest transition in Louisiana. Plant and Soil 280: 7-21.
Bitencourta, D.G.B, W.S. Barros, L.C. Timm, D. She, L.H. Penning, J.M. Barbat Parfitt \& K. Reichardt 2016. Multivariate and geostatistical analyses to evaluate lowland soil levelling effects on physico-chemical properties. Soil \& Tillage Research 156: 63-73.

Bitter, J.H., S. Van Dommele \& K.P. De Jong 2010. On the virtue of acid-base titrations for the determination of basic sites in nitrogen doped carbon nanotubes. Catalysis Today 150(1-2): 61-66.

Cambardella, C.A., T.B. Moorman, T.B. Parkin, D.L. Karlen, J. M. Novak, R.F. Turco \& A.E. Konopka 1994. Field scale variability of soil properties in Central Iowa soils. Soil Science Society of America Journal 58: 1501-1511.

Candela, L., R.A. Olea \& E. Custodio 1988. Lognormal kriging for the assessment of reliability in groundwater quality control observation networks. Journal of Hydrology 103: 67-84.

Cobo, G.J., G. Dercon \& T. Yekeye 2010. Integration of mid-infrared spectroscopy and geostatistics in the assessment of soil spatial variability at landscape level. Geoderma 158(3-4): 398-411.

Davidson, A. \& F. Csillag 2003. A comparison of nested analysis of variance (ANOVA) and variograms for characterizing grassland spatial structure under a limited sampling budget. Canadian Journal of Remote Sensing 29: 43-56.

Dai, F., Q. Zhoua, Z. Lv, X. Wang \& G. Liu 2014. Spatial prediction of soil organic matter content integrating artificial neural network and Ordinary Kriging in Tibetan Plateau. Ecological Indicators 45: 184-194.

F.J.P. Eagles \& S.F. McCool 2002. Tourism in national parks and protected areas: planning and management.

Elshorbagy, A., G. Corzo, S. Srinivasulu \& D.P. Solomatine 2010. Experimental investigation of the predictive capabilities of data driven modeling techniques in hydrology - Part 1: Concepts and methodology. Hydrology and Earth System Science 14: 1931-1941.

ESRI 2013. An Overview of the Interpolation Toolset. Available at: http://help.arcgis. com/en/arcgisdesktop/10.0/help/index. html\#/An_overview_of_the_Interpolation_ tools/009z00000069000000/.

ESRI 2012. Understanding Cokriging. Available at: http://webhelp.esri.com/arcgisdesktop/9.3/index. cfm?TopicName=Understanding_Cokriging $\rangle$.

Franzluebbers, A.J. 2002. Soil organic matter stratification ratio as an indicator of soil quality. Soil \& Tillage Research 66: 95-106.

Glendell, M., S.J. Granger, R. Bol \& R.E. Brazier 2014. Quantifying the spatial variability of soil physi$\mathrm{cal}$ and chemical properties in relation to mitigation of diffuse water pollution. Geoderma 214-215: 25-41.

Goovaerts, P. 1999. Geostatistics in soil science: state-of-the-art and perspectives. Geoderma 89: 1-45.

Ghorbani, A., J. Sharifi, A.H. Kavianpoor, B. Malekpour \& F.M.A. Gheshlagh 2013. Investigation on ecological characteristics of Festuca ovina L. in 
southeastern rangelands of Sabalan. Iranian Journal of Range and Desert Research 20(2): 379-396.

Ghorbani, A., V. Ahmadalei \& A. Asghari 2014. Study the effect of distance from village on plant diversity and composition in rangeland of southeastern Sabalan. Iranian Journal of Rangeland 8(2): 178-191.

Ghorbani, A., M. Abbasi Khalaki, A. Asghari, A. Omidi \& B.Z. Hesari 2015. Comparison of some effective environmental factors on the distribution of Artemisia fragrans and Artemisia austriaca in southeast faced slopes of Sabalan. Iranian Journal of Rangeland 9(2): 129-141.

Garten, Jr., C.T., S. Kang, D.J. Brice, C.W. Schadt \& J. Zhou 2007. Variability in soil properties at different spatial scales $(1 \mathrm{~m}-1 \mathrm{~km})$ in a deciduous forest ecosystem. Soil Biology \& Biochemistry 39: 2621-2627.

Gong, G., S. Mattevada \& S.E. O’Bryant 2014. Comparison of the accuracy of Kriging and IDW interpolations, in estimating groundwater arsenic concentrations in Texas. Environmental Research 130: 59-69.

Hockings, M. 2009. Systems for Assessing the Effectiveness of Management in Protected Areas. BioScience 53(9): 823-832.

Johnson, R.M., R.G. Downer, J.M. Bradow, P.J. Bauer \& E.J. Sadler 2002. Variability in Cotton Fiber Yield, Fiber Quality, and Soil Properties in a Southeastern Coastal Plain. Agronomy Journal 94: 1305-1316.

Kettler, T.A., J.W. Doran \& T.L. Gilbert 2001. Simplified method for soil particle-Size Determination to Accompany Soil-Quality Analyses. Soil Science Society of America 65: 849-852.

Li, L., Y.H. Xia, S.J. Liu, W. Zhang, X. Chen, H. Zheng, H. Qiu, X. He \& Y. Su 2015. Modified method for estimating organic carbon density in discontinuous Karst soil using ground-penetrating radar and geostatistics. Mountain Science 12(5): 1229-1240.

Liu, X., K. Zhao, J. Xu, M. Zhang, B. Si \& F. Wang 2008. Spatial variability of soil organic matter and nutrients in paddy fields at various scales in southeast China. Environmental Geology 53: 1139-1147.

Liu, X., W. Zhang, M. Zhang, D.L. Ficklin \& F. Wang 2009. Spatio-temporal variations of soil nutrients influenced by an altered land tenure system in China. Geoderma 152: 23-34.

Long, X.H., J. Zhao, Z.P. Liu, Z. Rengel, L. Liu, H.B. Shao \& Y. Tao 2014. Applying geostatistics to determine the soil quality improvement by Jerusalem artichoke in coastal saline zone. Ecological Engineering 70: 319-326.

Majaliwa, J.G.M., R. Twongyirwe, R. Nyenje, M. Oluka, B. Ongom, J. Sirike, D. Mfitumukiza, R. Azanga, R. Natumanya, R. Mwerera \& B. Barasa 2010. The Effect of Land Cover Change on Soil Properties around Kibale National Park in South Western Uganda. Applied \& Environmental Soil Science, 10(3): 1-7.

Miller, M.P., M.J. Singer \& D.R. Nielson 1988. Spatial variability of wheat yield and soil properties on complex hills. Soil and Environmental Science societies 52(4): 1133-1141.
Olea, R.A. 2006. A six-step practical approach to semivariogram modeling. Stochastic Environmental Research \& Risk Assessment 20: 307-318.

Pardo-Iguzquiza, E., M, Chica-Olmo J.A. LuqueEspinar \& V. Rodriguez-Galiano 2015. Compositional Cokriging for mapping the probability risk of groundwater contamination by nitrates. Science of the Total Environment 532: 162-175.

Patel, B.K., S.A. Jain, M.S. Jagtap, K.P. Patel \& D.H. Patel 2014. Study of presence of available potassium in soil of Lunawada Taluka territory. Archives of Applied Science Research 6(1): 79-84.

Reimann, C. \& P. Filzmoser 2000. Normal and lognormal data distribution in geochemistry: death of a myth. Consequences for the statistical treatment of geochemical and environmental data. Environmental Geology 39: 1001-1014.

Robinson, T.P. \& G. Metternicht 2006. Testing the performance of spatial interpolation techniques for mapping soil properties. Computers \& Electronics in Agriculture 50: 97-108.

Sajid, A.H., R.P. Rudra \& G. Parkin 2013. Systematic evaluation of Kriging and inverse distance weighting methods for spatial analysis of soil bulk density. Canadian Biosystem Engineering 55: 1-13.

Sato, H.J., C.C. de Figueiredo, R.L. Marchao, B.E. Madari, L.E.C. Benedito. J.G. Busato, D.M. de Souza 2014. Methods of soil organic carbon determination in Brazilian savannah soils. Scientia Agricola 71(4): 302309.

Sauer, T.J., C.A. Cambardella \& D.W. Meek 2006. Spatial variation of soil properties relating to vegetation changes. Plant \& Soil 280: 1-5.

Sheikh, J.E. \& J.H. Sheikh 2006. Composition and species diversity of vertebrates in Ardabil Province. Environmental Science 10: 35-50.

Varallyay, G., J. Szabo, L. Pasztor \& E. Micheli 1998. A database for sustainable agriculture and environmental protection in Hungary. In: 'Land Information Systems. Developments for Planning the Sustainable Use of Land Resources'. European Soil Bureau Research Report 164: 151-164.

Wang, Y., X. Zhang \& C. Huang 2009. Spatial variability of soil total nitrogen and soil total phosphorus under different land uses in a small watershed on the Loess Plateau, China. Geoderma 150: 141-149.

Wang, J., R. Yang \& Z. Bai 2015. Spatial variability and sampling optimization of soil organic carbon and total nitrogen for Minesoils of the Loess Plateau using geostatistics. Ecological Engineering 82: 159-164.

Webster, R. \& M. Oliver 2001. Geostatistics for Environmental Scientists.

Wei, J.B., D.N. Xiao, H. Zeng \& Y.K. Fu 2008. Spatial variability of soil properties in relation to land use and topography in a typical small watershed of the black soil region, northeastern China. Environmental Geology 53: 1663-1672.

Worsham, L., D. Markewitz \& N. Nibbelink 2010. Incorporating spatial dependence into estimates of 
soil carbon contents under different land covers. Soil Science Society of America 74: 635-646.

Wu, J., W.A. Norvell \& R.M. Welch 2006. Kriging on highly skewed data for DTPA- extractable soil Zn with auxiliary information for $\mathrm{pH}$ and organic carbon. Geoderma 134: 187-199.

Yan, L.I., S.H.I. Zhou, W.U. Ci-Fang, L.I. Hong-Yi \& L.I. Feng 2007. Improved prediction and reduction of sampling density for soil salinity by different geostatistical methods. Agricultural Sciences in China 6: 832-841.

Yasrebi, J., M. Saffari, H. Fathi, N. Karimian, M. Moazallahi \& R. Gazni 2009. Evaluation and comparison of ordinary Kriging and Inverse Distance Weighting methods for prediction of spatial variability of some soil chemical parameters. Research Journal of Biological Sciences 4: 93-102.

Zinck, J.A. 1995. Soil Survey: Perspectives and Strategies for the $21^{\text {st }}$ Century. World Soil Resources Reports 128 .

\section{Authors}

\section{Ardavan Ghorbani}

is an Associate Professor at the University of Mohaghegh Ardabili. He was born in 1965 in Khalkhal County, Ardabil Province, northwest Iran. In 2006, he received a $\mathrm{PhD}$ in Range Management from the University of South Australia. His main research interest is macro ecology (plant ecology) using GIS and remote sensing technologies. at the E-mail: a ghorbani@uma.ac.ir

\section{Samaneh Mohammad Moghaddam?}

is an $\mathrm{PhD}$ candidate. She was born in 1986 in Mashhad, Khorasan Province, northeast Iran. In 2013, she received an MSc in Range Management Science from the University of Mashhad. Her research interest is the modelling of rangeland production and climate change. E-mail: moghadam.samaneh@ymail.com

\section{Kazem Hashemi Majd²}

is an Associate Professor at the University of Mohaghegh Ardabili. He was born in 1975 in Ardabil, northwest Iran. His research interest is soil science (soil chemistry in particular). E-mail: k_hashemi@ uma.ac.ir

\section{Naser Dadgar ${ }^{2}$}

is a graduated MSc student. He was born in 1988 . In 2013, he received an MSc in Soil Science from the University of Mohaghegh Ardabili, Ardabil, Iran. His research interests are soil science and geostatistics.

${ }^{1}$ Department of Range \& Watershed Management, University of Mohaghegh Ardabili, Ardabil, Iran.

${ }^{2}$ Department of Soil Science, University of Mohaghegh Ardabili, Ardabil, Iran. 